\title{
Aptamer-based Therapeutics and their Potential in Radiopharmaceutical Design
}

\author{
Catia S. M. Ferreira ${ }^{1,2}$ and Sotiris Missailidis ${ }^{1 *}$ \\ ${ }^{l}$ Chemistry Department; The Open University; Walton Hall; Milton Keynes, MK7 6AA; s.missailidis@open.ac.uk. \\ ${ }^{2}$ Ontario Cancer Institute; University of Toronto; 610 University Avenue; Toronto; Ontario, M5G 1 J6 - Canada
}

\begin{abstract}
Aptamers, short, single stranded oligonucleotide entities, have been developed in the past 15 years against a plethora of targets and for a variety of applications. These range from inhibition of receptors and enzymes to the identification of small molecules in sensor applications, and from the development of targeted therapeutic to the design of novel diagnostic and imaging agents. Furthermore, aptamers have been designed for targets that cover a wide range of diseases, from HIV to tropical diseases, cancer and inflammation. Their easy development and flexibility of use and manipulation, offers further potential. In this paper we review their selection and consider some of the recent applications of aptamers in the design of radiopharmaceuticals for the targeted radiotherapy and medical imaging of disease.
\end{abstract}

Key words: Aptamers, Radiopharmaceuticals, SELEX, Radiolabeling, Medical imaging

\section{INTRODUCTION}

Aptamers (from the Greek word meaning "to fit") are short, 50-100 base-long, oligonucleotides capable of recognizing a wide range of target molecules, and bearing a group of characteristics important for the development of novel diagnostic and therapeutic strategies.

Aptamers can be composed of RNA, DNA or modified bases, and are selected from vast populations of random sequences, through a combinatorial approach known as systematic evolution of ligands by exponential enrichment (SELEX). The selected sequences have the ability to recognize specific ligands by forming binding pockets and can bind to nucleic acids (Le Tinevez et al., 1998; Pileur et al., 2003), proteins (Bock et al., 1992; Lupold et al., 2002) or small organic compounds (Berens et al., 2001; Burgstaller et al.,
1996). Aptamer recognition affinity and specificity is comparable to those of monoclonal antibodies and aptamers can be selected to recognize and bind a wide range of targets, including toxic compounds and inherently non-immunogenic molecules that antibodies cannot be raised against. Furthermore, as aptamers are 10 to 100 times smaller than antibodies, they are expected to achieve higher tumour penetration than their counterparts (Jayasena 1999).

These small single-stranded nucleic acids are claimed to act as mimics of antibodies in that they can recognise molecular targets with high specificity and are able to carry therapeutic agents, radioisotopes, directly to solid tumour masses or to individual cells that may have metastasised with greater efficiency (Brody and Gold, 2000; Cerchia et al., 2002; Sooter and Ellington, 2002).

\footnotetext{
${ }^{*}$ Author for correspondence
} 
When compared to antibodies, aptamers have advantages and disadvantages as therapeutic and biological reagents (Jayasena, 1999). Aptamers present faster tissue penetration and wider applicability and present the opportunity for simple base modifications to improve functionality by comparison. Furthermore their small size (molecular weights between 3000 - 20000) may reduce steric hindrance, increasing surface coverage during immobilization (Deng et al., 2001). The in vitro selection process (SELEX) can be more precisely monitored than can organismal immunization, and the affinities and specificities of aptamers can thus be better tailored than can those of antibodies. Aptamers can be more readily engineered than antibodies for biological/medicinal use (Jayasena, 1999).

Once identified, aptamers can be reliably synthesized by automated methods. During synthesis, aptamers can be easily modified to facilitate further modifications such as attachment points for enzymes or a variety of other reagents, and the introduction of modified bases for nuclease resistance (Fig. 1) (Brody and Gold, 2000; Eaton et al., 1997; Gewirtz, 1999). Furthermore, aptamers can be stored until needed and are resistant to denaturation and degradation when lyophilised.
Due to the high degree of specificity and targeted nature of aptamer behaviour towards the target molecule, it is expected that the dosage of therapeutic aptamer to be used can be the smaller, this strategy may reduce costs and alleviate bystander effects caused by the aptamer-conjugate toxic side effects (Gewirtz, 1999). Furthermore, more pharmokinetic data is readily available that demonstrates aptamer quick clearance. PEGylation is currently been studied to improve aptamer circulation for longer periods of time (Pendergrast et al., 2005).

On the other hand, aptamers are still expensive to produce in high quantities, mainly due to the fact that aptamers are a new entity and the technology has not evolved yet to generate large quantities of the entity at reasonable cost. Furthermore, the addition of modifications to the basic oligonucleotide aptamer to protect from nuclease degradation and improve pharmacokinetic properties further increases production costs. Thus, aptamers are still in their infancy in terms of use in the clinic. But their properties and development has attracted and still attracts increasing interest, demonstrated by the number of publications on aptamers and the current pipeline of such molecules in diagnostic and therapeutic applications.

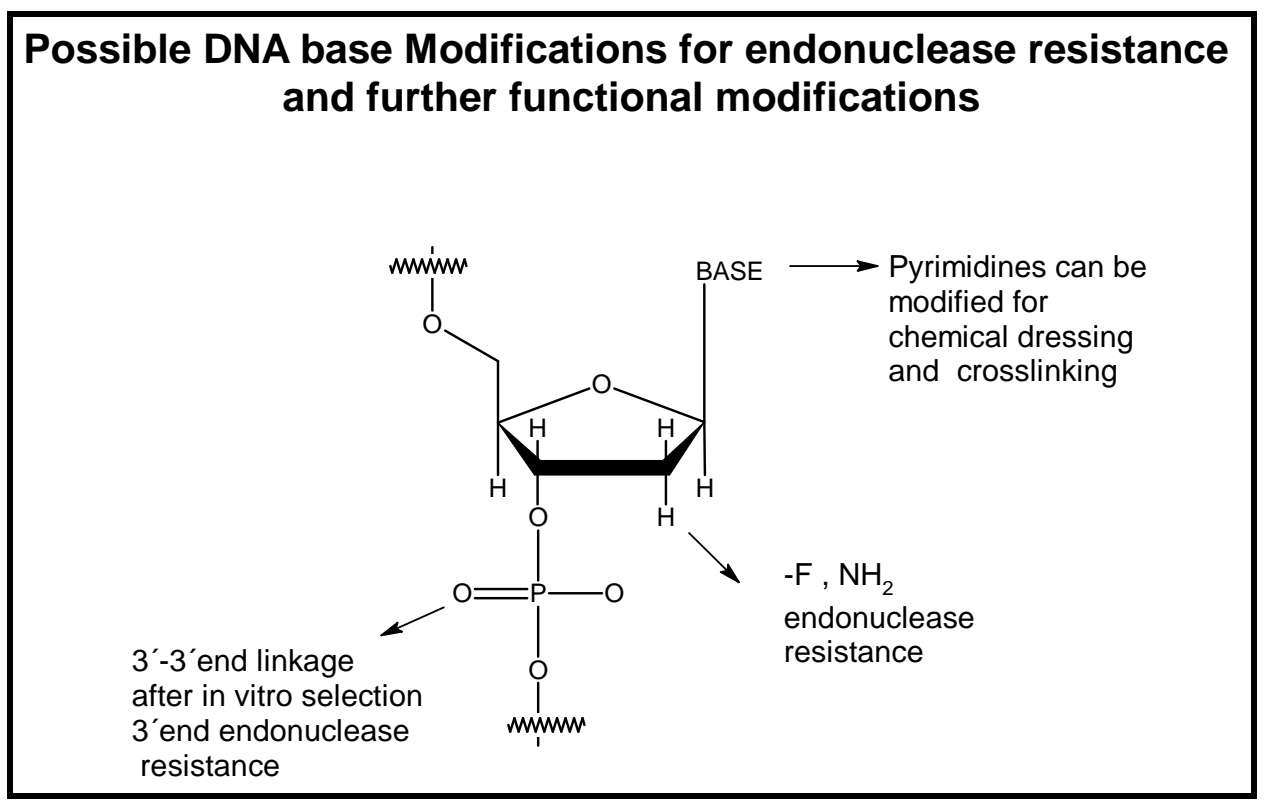

Figure 1 - Possibilities for chemical modification of a nucleotide base 
Aptamers have been selected for various purposes, making use of their high specificity, versatility and affinity in target recognition. Examples include aptamers that recognize proteins, peptides, dyes, amino acids, nucleotides, and drugs among others, to act as biosensors (Potyrailo et al., 1998), probes (Pavski and Le, 2001) and anti-clotting agents (Bock et al., 1992), whilst the first aptamer has made it to the market gaining FDA approval.

\section{Selex (Systematic Evolution of Ligands by Exponential Enrichment)}

SELEX is an iterative process used to identify an aptamer to a chosen molecular target. The method is based on standard molecular biological techniques and can be carried out following different experimental protocols according to the researcher's choice. The process is constituted of three main phases: (1) selection, (2) partitioning, and (3) amplification (see Fig. 2).

The process starts with the design of a large "library" of nucleic acid molecules generated by solid phase technology. Each molecule in the library (often as many as $10^{15}$ different compounds) contains a unique nucleotide sequence that can theoretically adopt a unique three-dimensional shape. Some of the most common structures observed, include hairpins, Gquadruplexes, superloops etc. The SELEX library is generally designed with flanking primers at either side to allow for amplification of the selected pool and a variable region of anything from 15 up to 100 nucleotides.

The selection phase is designed to identify those molecules with the greatest affinity for the target of interest. The library of nucleotide sequences is exposed to the target (a protein, small molecule, or supramolecular structure) by a variety of methods and allowed to incubate for a period of time. The molecules in the library with weak or no affinity for the target will remain free in solution, while those with increased capacity to bind will tend to associate with it.

The partitioning phase is designed to any of several methods used to physically separate the aptamer: target complexes from the unbound molecules in the mixture, effectively separating the true binders from the weak or non-binders. The unbound molecules are separated and discarded. The target-bound molecules, among which are the highest affinity aptamers, are purified away from the target and used for the subsequent steps in the SELEX process.

In the amplification phase, the captured, purified sequences are enzymatically amplified using PCR amplification, to generate a new library of molecules that is substantially enriched for those aptamers that can effectively bind to the target. The enriched library is used to initiate a new cycle of selection, partitioning and amplification.

After a range of 5-15 cycles of the complete process, the library of molecules is reduced from trillions of unique sequences to a small number that bind tightly to the target of interest. Individual molecules in the mixture are then isolated, their nucleotide sequences are determined, and their binding affinity and specificity properties are characterised. In some cases, isolated aptamers are further refined to eliminate any nucleotides that do not contribute to target binding or aptamer structure.

The first SELEX experiment on single stranded RNA oligonucleotides was published by Tuerk and Gold, when investigating the bacteriophage T4 DNA polymerase (Tuerk and Gold, 1990). In literature we can now identify a large number of aptamers selected for a very broad spectrum of targets. Furthermore, the first aptamer has recently successfully reached the pharmaceutical market. This is an anti-VEGF aptamer for the treatment of macular degenerative disease that exerts its action by attacking the neo-vascularization characteristic of this disease, under the name of Macugen (Eyetech/Pfizer) (Ng et al., 2006; Kourlas and Schiller, 2006).

\section{Dna and RNA as Aptamers}

The use of single stranded oligonucleotide aptamers allows a large variety of DNA or RNA shapes and sequences to be explored. RNA or DNA usually create a specific cavity to enclose and recognize a small molecule, or adapt to the enclosure of a bigger molecule. Aptamers are thought to be mainly non-rigid molecules in the absence of their protein-binding partner and folded upon binding. The exception to the rule is found in G-quadruplexes such as the DNA thrombin aptamer that seems to hold its structure even in the absence of its partner. The sampling of "shape space" in SELEX libraries has proven effective for the isolation of ligands to targets that are not known to interact with nucleic acids physiologically (Macaya et al., 1995). The known 
fact that proteins possess extensive surfaces with ridges, grooves, projections, and depressions, all covered with numerous H-bond donors and acceptors, suggests that proteins should be excellent targets for aptamer selections. The detection of the first nucleic acid aptamers to a protein that does not normally interact with RNA or DNA was a single stranded DNA aptamer to thrombin, indicating the beginning of a new class of thrombin inhibitors (Bock et al., 1992; Griffin et al., 1993).

Numerous selections of this type have now been reported, and it appears that it is possible to find high-affinity nucleic acid aptamers for most proteins. This has made in vitro selection of aptamers an effective method for generating reagents that interfere with the activities of extracellular proteins (proteases, cell-surface receptors and their ligands, auto-reactive antibodies), implicated in diverse pathological conditions. Aptamers that bind to and interfere with the action of proteins implicated in pathological conditions could potentially be used as pharmaceutical agents. Numerous aptamers are now being developed as therapeutic agents. Aptamer have clear advantages for their use as therapeutics. Aptamer pharmacokinetics shortages of the past are now being addressed with appropriate chemical modifications to improve their stability in serum and their circulation time. Aptamers have now been reported to be in circulation in animal models up to eight hours when appropriately modified (Cerchia et al., 2002; Santulli-Marotto et al., 2003).

Structure determination of a number of these aptamers has also lent insight into the folding capabilities and adaptive properties of nucleic acids in order to recognize their cognate substrates (Feigon et al., 1996). This recognition has been shown to often rely strongly on the exceptional propensity of the nucleic acids to assume secondary and tertiary structural elements as referred above (Dieckmann et al., 1996; Patel, 1997). The number of possible thermodynamically stable structural variants available for an oligonucleotide sequence is much higher than the number of variants available for a peptide sequence of the same length. This is simply based on the ability of nucleotide bases to interact with each other through canonical Watson-Crick as well as unusual base pairing. The existence of oligonucleotide sequences that could assume a myriad of shapes within a random sequence library is the basis for the remarkable success of generating aptamers to a wide variety of target molecules (Lin and Patel, 1996; Patel and Suri, 2000; Patel et al., 1997; Ye et al., 1999).

RNA has intrinsic properties that lead to the formation of a variety of elaborate structures, some of which are able to catalyse reactions and others are able to function as receptors and ligands. Natural DNA acts almost without an exception as an informational macromolecule that exists primarily as a base-paired duplex. Predominantly unstructured in solution, aptamers fold upon association with their ligands into molecular architectures in which the ligand becomes an intrinsic part of the nucleic acid structure (Hermann, 2000). Single stranded DNAs are rarely encountered in nature, and even less frequently do these single stranded DNAs form shapes, other than the usual duplex, that serve a functional role. A number of compelling arguments can be made in support of the notion that certain DNAs are capable of forming structures that mimic those of folded RNAs, including ribozymes. Furthermore our understanding of nucleic acid recognition elements has also broadened as in vitro selection and selective evolution has been used to identify nucleic acid motifs with unique folding and ligand-binding properties (Patel, 1997).

\section{Molecular Basis of Aptamer Binding}

The molecular characteristics of aptamer interactions with a variety of molecular targets have been studied using nuclear magnetic resonance spectroscopy (NMR). These experiments offered several interesting insights into the interactions: (i) aptamers are folded into unique overall shapes to form intricate binding pockets to accommodate their targets; (ii) functional groups scattered on an aptamer are brought in close proximity to form a cluster of molecular forces that specify target interaction; (iii) aptamers discriminate molecules that are closely related to cognate targets at the atomic level. NMR studies of several aptamer-target complexes also indicated that small molecular targets are buried within the binding pockets of aptamers, leaving very little surface to interact with a second molecule (Berens et al., 2001; Dieckmann et al., 1997; Fan et al., 1996; Patel, 1997). 


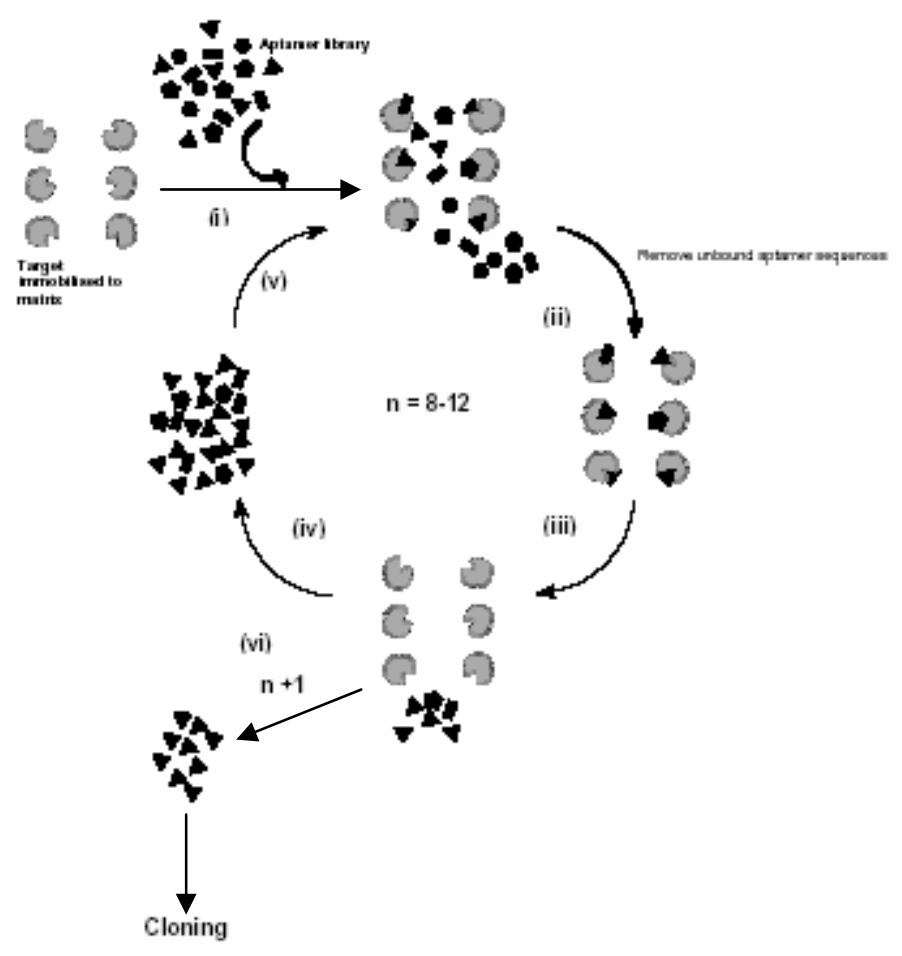

Figure 2 - Representation of the interactive SELEX process: i) Incubate aptamer library with immobilised target, ii) Wash sample to remove unbound sequences, iii) Elute bound aptamers from target, iv) Amplify selected aptamers using PCR, v) Incubate selected aptamers with target, vi) After $n+1$ rounds, selected aptamers are cloned and sequenced

The structure of an argininamide-DNA complex is one of several examples emerging recently that contributes to the understanding of how molecules adapt to recognize their substrate. Binding characteristics of argininamide are critical in the formation of the structural loop conformation of this DNA aptamer. The binding pocket is formed by unusual interactions that include the $\mathrm{C} 16$ residue looping out of sequence to form a WatsonCrick base pair across the loop with G9, and formation of reverse G14-T10 wobble and reverse A7-C15 hoogsteen pairs. These interactions are definitive elements in forming the deep kink in the DNA structure that encloses the argininamide ligand (Robertson et al., 2000).

Target affinity of DNA aptamers is often based on the guanine quartet as the fundamental secondary structure unit. In general, guanine quadruplex structures, stabilized by guanine quartets, can be constructed from one, two or four oligonucleotide strands. When four separate strands are involved, a linear quadruplex results, with all deoxyguanosine nucleosides in the anti conformation about the glycosilic bond. In the other two cases, the quadruplexes involve folded strands and there is an alteration between syn and anti conformations for these residues (Williamson, 1994). G quadruplexes are remarkably stable both kinetically and thermodynamically because of tight association of cations with the guanine residues (Kankia and Marky, 2001).

One of the first described examples of a proteinspecific DNA aptamer was by Bock and his colleagues (Bock et al., 1992), who isolated a 15nucleotide DNA aptamer that binds to and inhibits the function of human thrombin. This DNA 
consists of stacked 'G-quartet' structures, similar to the structures that are believed to form in certain natural single-stranded DNAs. Two groups of scientists, Macaya et al.(1993) and Tsiang et al.(1995) have also described new thrombinspecific DNA aptamers that also form 'Gquartets'. These new aptamers include additional paired bases that in some cases allow for a more tight binding to the thrombin than do aptamers lacking those base pairings. In addition to the thrombin-specific G-quartets already illustrated, several other guanosine-rich DNA sequences have been identified within in vitro selected DNAs. One such G-quadruplex based aptamer, actually formed as a dimer, is the anti-nucleolin aptamer currently in clinical trials by Antisoma Ltda (www.antisoma.com).

RNA and DNA aptamers have been selected to bind the reverse transcriptase of HIV-1, and it was found that the aptamers bound and inhibited the activity of their target. Scheneider and co-workers, in 1995 (Schneider et al., 1995), used in vitro selection to isolate aptamers that inhibit the HIV-1 reverse transcriptase (RT). After 15 rounds of selection from a random-sequence pool, DNA strands representing six different structural classes were isolated. The predicted structural elements of these molecules include internal bulges, stemloops and pseudoknots, a showcase for the structural diversity of single stranded DNA. Although HIV-1 RT showed a natural affinity for DNA, with a $\mathrm{K}_{\mathrm{d}} \sim 1.4 \mu \mathrm{M}$, several of the isolated aptamers showed a 1000 -fold increase in affinity for the enzyme. It was interesting to see that members of both classes of aptamers could act both as primer/templates for HIV-1 RT and other DNA-polymerising enzymes. Furthermore RNA aptamers were also found to bend into pseudoknot structure and fashioned complexes with reverse transcriptase with a $\mathrm{K}_{\mathrm{d}}$ of $5 \mathrm{nM}$ (Famulok et al., 2001).

Aptamers have been shown to be neutralizers of R5 strains of the human deficiency virus 1 infection by specifically binding to the CCR5binding site on gp120 (Dey et al., 2005; Khati et al., 2003), to recognize the Tenascin- $\mathrm{C}$, an extracellular protein on the surface of glioblastoma cell line found in the tumour matrix (Daniels et al., 2003), or to specifically inhibit the accumulation of protease-resistant forms of prion precursor protein (PrP) (Rhie et al., 2003; Sayer et al., 2004). Catalytic DNA aptamers have also been described by Breaker et al. (1997) and a RNA-cleaving aptamer by Li's group in 2006 (Schlosser et al, 2006). Thus, there is an increasing pool of biologically active aptamers about which relatively little is known concerning their structure and stability and their relationship to function.

The objective of many aptamer selections for protein targets is to recover DNA molecules that specifically bind enzymes or receptor proteins and interfere with the receptor pathway. In 1996, Schimmel and Hale (1996) reported the selection of a unique type of DNA aptamer for the isoleucyl-tRNA synthetase of Escherichia coli. When this aptamer binds to the target it was found to promote the aminoacyl adenylate editing reaction that is typically induced upon binding of corresponding tRNA, behaving as a mimic of the natural binder, allowing the study of this interaction and an insight into the properties of receptor pocket and binder structure.

RNA libraries bearing suitable modifications at the 2 ' position of the sugar have yielded aptamers that are nuclease resistant, thus circumventing the potential limitation of RNA aptamers to measure analytes in biological fluids that contain nucleases. On the other hand, compared with the unmodified RNA sequences, unmodified DNA sequences are generally more nuclease resistant. In fact, DNA aptamers with or without terminal modifications have been effective in biological fluids (Bock et al., 1992; Griffin and Leung, 1993).

Therefore, it is reasonable to assume that DNA aptamers without further modifications could perform in diagnostic assays in which aptamers may come into contact with biological fluids for a brief period of time. If necessary, additional protection from exonucleases can be provided through terminal capping with small molecules such as an amine linker, a phosphate group, or an inverted thymidine residue and other unnatural bases (Fig. 3).

For most diagnostic formats, terminal modification of aptamers is expected to be common and provides a route to conjugate aptamers either to reporter molecules or to solid supports. Modified nucleotides have been introduced into selection experiments, resulting in the isolation of aptamers that are surprisingly stable in vivo (Lathan and Toole, 1994).

Additionally the binding affinity and specificity of an aptamer could be further improved by subjecting the sequence to a second selection (doped selection), in which case a biased library is created based on the primary sequence of an 
existing aptamer. The biased library increases the complexity of molecules, mostly represented by the variants of the primary aptamer, which were lost in the early stages of selection in the completely randomised library by random factors (Knight and Yarus, 2003).

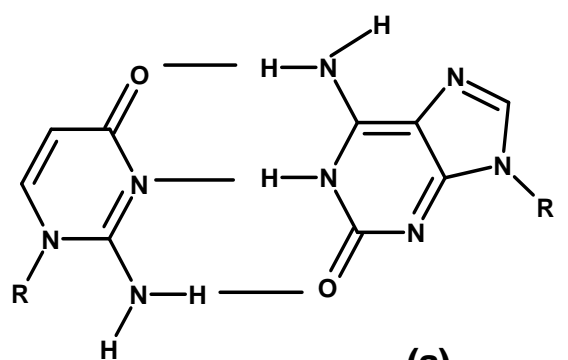

(a)

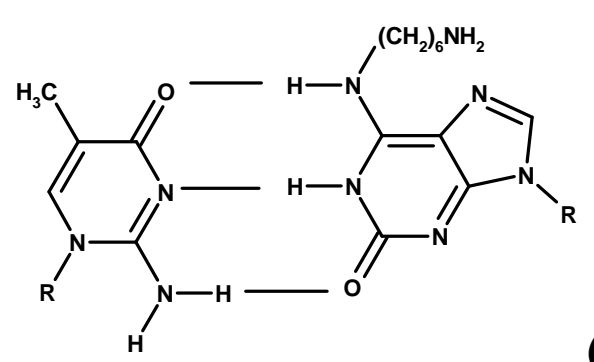

(b)

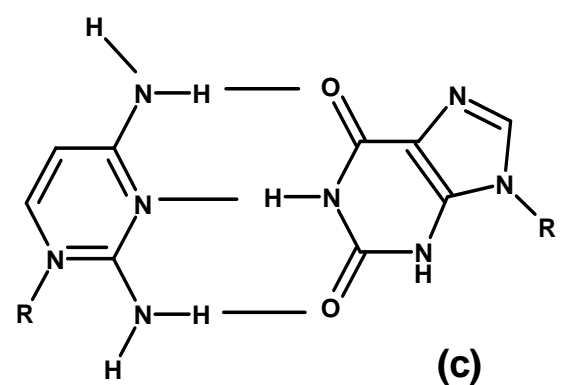
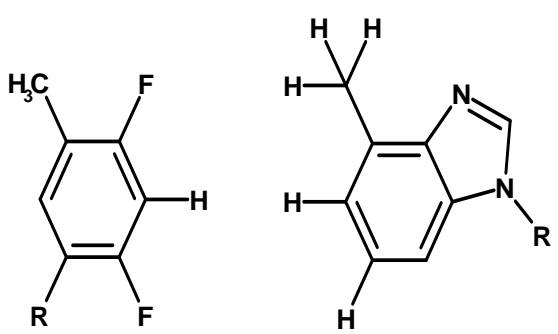

(d)

Figure 3 - Examples of chemical structures of unnatural base pairs that have been incorporated by either DNA or RNA polymerases or both. (a) isoC- isoG (Picirilli et al, 1990); (b) $\mathrm{Me}_{\text {isoc- }}$ 6-AH-isoG (Tor, 1993); (c) 2,6-diaminopyrimidine- Xanthine (Picirilli et al., 1990); (d) 2,4-difluorotoluene- 6-methyl purine- mimic the shape of an A-T base pair (Guckian et al., 1998)

\section{Aptamers as Therapeutics}

The idea of using aptamers as therapeutic molecules has evolved from observations of nature, and more specifically from the observation of virus and their method of control of the host organism.

Several groups have made the suggestion that aptamers are at the forefront of the list of the most promising agents as potential nucleic acid pharmaceuticals. A whole series of aptamers that can bind protein targets inside and outside the cell can be found in the literature, which illustrates the potential of DNA or RNA aptamers as therapeutic modalities. Examples include aptamers to HIV related targets (Andreola et al., 2001; de Soultrait et al., 2002; Duzgunes 2001), hepatitis C (Biroccio et al., 2002; Hwang et al., 2000; Vo et al., 2003), Trypanosoma cruzi (Homann and Goringer, 1999; Homann and Goringer, 2001; Ulrich et al., 2002), prion proteins (Sayer et al., 2004; Weiss et al.,
1997), thrombin (Bock et al., 1992; Griffin et al., 1993; Holland et al., 2000), anti-angiogenesis vascular endothelial growth factor (Blank et al., 2001; White et al., 2003), prostate specific membrane antigen (Lupold et al., 2002), among many others. Aptamers against the nucleolin are currently in clinical trials for the treatment of cancer with very promising results (www.antisoma.com). One of the success stories is the anti-VEGF aptamer as referred before (www.eyetk.com). The pegylated anti-VEGF aptamer has been recently FDA approved, and it was developed to target the abnormal blood vessel growth and leakage that leads to blindness (Carrasquillo et al., 2003). The anti-VEGF aptamer neutralizes the abnormal VEGF presence in the eye thus preventing its binding to the receptor. The anti-VEGF aptamer has demonstrated efficacy in several in vitro and in vivo models. 
Another success story is the E2F decoy aptamer that binds the transcription factor E2F, aimed at reducing the proliferation of cardiac and vascular cells in cardiovascular diseases as well as in the development of malignancies (Fabbrizio et al., 1999). This aptamer is a naturally developed aptamer, because it contains a known consensus sequence that is found naturally in the human body. This aptamer is currently in Phase three trials study by Corgenetech, Inc. and being evaluated for its efficacy at restraining coronary and peripheral vascular graft failure.

Aptamers also present the possibility to work as antidotes and more importantly the potential of creating a self-antidote, simply through the creation of a self-aptamer that disrupts the interaction with the target, thus allowing for a controlled therapy. This feature is not usually present in any of other biological therapy.

However, drawbacks such as their cost, synthesis, bioavailability, pharmacokinetics properties and delivery hindered aptamers from immediate application in the pharmaceutical industry and more importantly the fact that antibodies are a proven biological therapeutic and thus aptamers would need to be more flexible, more stable and more efficient than antibodies in order to replace the later. Thus, aptamer development needs to focus on their advantages in relation to other more proven biological therapeutics and the possibilities they present.

\section{Aptamers as Radiopharmaceutical Tools}

The advent of techniques such as SELEX has allowed the study and manipulation of nucleic acids and has propelled the discovery of molecular tools for the treatment of human disease. Equipped with these new tools, the implementation of simple steps for the formation of a new class of therapeutic agents was one step away. The idea of attaching radionucleotides to a biological molecule is not new (Bernardo-Filho et al., 2005). Long and detailed studies have been carried out in the past with some success with antibodies, peptides or antisense targeting. Aptamer labelling was a natural step in the direction of molecular targeted radiopharmaceutical development, propelled both by the understanding of the biological properties of these molecules, specially their chemical malleability and pharmacokinetics, and the simplicity of the chemistry involved in the labelling of aptamers for pharmacoimaging and pharmacotherapy (Britz-Cunningham and
Adelstein, 2003; Cerchia et al., 2002; Urbain, 1999).

Two DNA aptamers directed at two separate exosites on the human alpha-thrombin have been evaluated for they're potential as thrombus imaging agents. Both aptamers were analysed and ODN2 was found to be suitable for imaging with rapid clearance rates. However, the conclusions of the study also found that the slow mass transfer to the clot worked against the in-vivo thrombindependent imaging (Doughan et al., 2003). More recently an aptamer that binds to the extracellular matrix protein Tenascin-C was $99 \mathrm{mTc}$-labeled and analysed for the potential use as radiopharmaceutical in a variety of animal models. In this study rapid uptake and rapid clearance of the radiolabeled aptamer from blood and other tissues provided clear tumour imaging, thus suggesting potentially imaging and therapeutic applications (Hicke et al., 2006).

\section{Aptamer Labeling with Radiometals}

The introduction of radiometals into aptamers has been carried out by chelation of the metal with a suitable binding ligand (bifunctional chelator), followed by conjugation to the aptamer via a reactive functional group. Such groups include a 3'-amino modification, or a 5'-linker equipped with an amino terminus, which enables the attachment of the complex through an amide bond. The chemistry is largely based on the chemistry developed for proteins and peptides.

Aptamer labeling with technetium, the most common radiometal used in imaging, has been reported by Hilger et al. (1998). The bifunctional N3S-type peptide-based chelator MAG2 was synthesized in the S-acetyl-protected form. Activation of the carboxylic acid with Nhydroxysuccinimide ester formation enabled conjugation to an L-Selectin binding aptamer through a 5'-(6-aminohexyl)-phosphato linker. Cleavage of the sulfur protection, followed by treatment with sodium pertechnetate yielded the Tc-aptamer complex in excellent yield (90-95\% yield). The same bifunctional chelator and linker were used by Schmidt et al. (2004) to label a series of locked nucleic acids. An interesting feature of aptamer labeling is the possibility to carry out the complexation step in the final stage of the conjugate synthesis, as aptamers do not get denatured even at high temperatures. This is particularly important in the case of short-lived isotopes. 
Charlton et al. (1997) have reported the labeling of an aptamer inhibitor of human neutrophil elastase with MAG2-complexed 99mTc. The comparison of the labeled aptamers with labeled a labeled $\operatorname{IgG}$ showed that the aptamer displayed rapid accumulation in the tumor and rapid clearance. Tumor-to-blood ratios after $2 \mathrm{~h}$ was approximated 4 in the case of the aptamer, while for the antibody it peaked at 3-4 at $3 \mathrm{~h}$. The superior T/B ratios were due to the rapid clearance of the aptamer conjugate from the non-target (non-inflamed) tissue, while there was little or no clearance of the IgG.

An anti-Tesascin-C aptamer (TTA1) was labeled with $99 \mathrm{mTc}$, and the biodistribution of the conjugate was investigated in glioblastoma and breast cancer tumor xenografts (Hicke et al., 2006). The impact of the metal chelate (MAG2Tc) on biodistribution was evaluated by conjugation to both TTA1 and PEG-ylated TTA1. The MAG2 moiety was conjugated to the oligonucleotide via a 5'-amino group. It was found that radiolabeling did not affect the affinity of the aptamer to Tenascin-C. The tumor-to-blood ratio was $>50$ three hours post injection, and $>180$ after $16 \mathrm{~h}$, while the control antibody required $40 \mathrm{~h}$ for a $\mathrm{T} / \mathrm{B}$ ratio of 5 .

An anti-MUC1 aptamer was labeled with technetium complexed with four different bifunctional chelators bearing carboxylic acid bioconjugatable functionalities (Borbas et al., 2007). The complexes were formed by reduction of the pertechnetate with sodium borohydride, followed by treatment with a solution of the chelator. The complexes were conjugated without isolation to a 3'-amino group in the aptamer in standard EDCI-mediated peptide bond formations. The chelators tested were commercially available MAG3, DOTA, meso- tetrakis (p-carboxyphenyl) porphyrin and a cyclen (1,4,7,10tetraazacyclododecane) derivatised with a methionine arm (MetCyc) (Fig. 4).

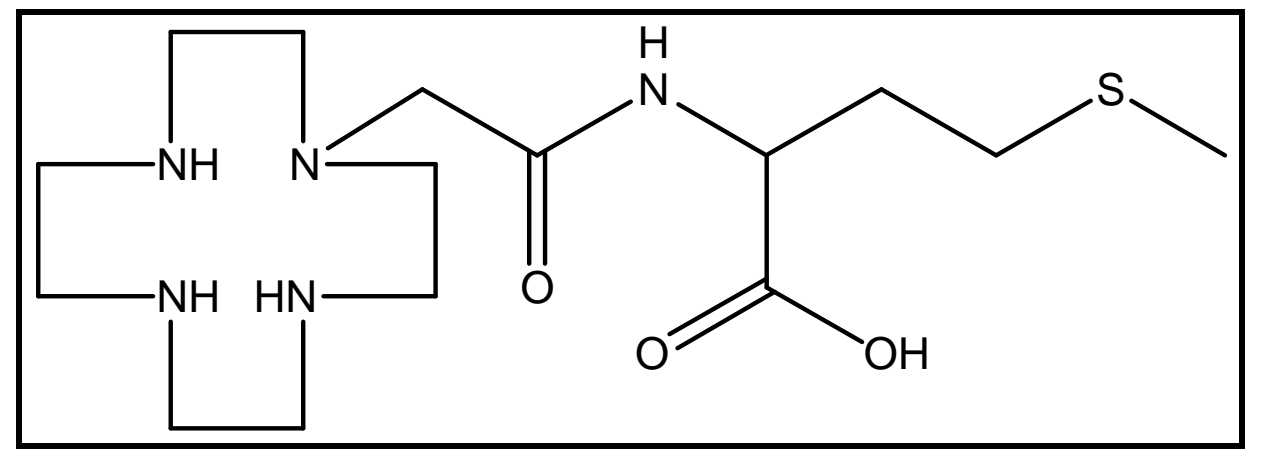

Figure 4 - The novel cyclen based ligand with a methionine arm offers additional stability for the metal, whilst the carboxylic group allows coupling to an amino-modified aptamer using standard peptide chemistry

The presence of four carboxylates in DOTA enabled the attachment of four aptamer molecules to a central complex. The increased molecular weight of the tetrameric conjugate as opposed to the monomeric ones resulted in increased tumor retention and improved pharmacokinetic properties. With the exception of the porphyrin, all the tested chelators performed suitably, and aptamer labeling was typically $>90 \%$. Although the porphyrin was an unappealing chelator for techentium, it could be much better suited for other radiometals, such as copper, as porphyrincopper(II) complexes are particularly stable.

\section{Antibodies VS Aptamers}

In various published studies, antibodies and aptamers have been extensively compared and scrutinized (Brody and Gold, 2000; Jayasena, 1999). Aptamers have been hailed as the new biological molecule with enough superiority to slowly replace antibodies. An account of these differences is summarised below.

Antibodies have, for many decades, been at the forefront of biological therapies, but their swift development has been countered by a variety of barriers that are being slowly overcome (Cosmas et al., 1993). The antibody identification process traditionally starts within an animal; this process allows for the creation of many specific antibodies 
with the physiological constraints already in place. However, the antibody generation against molecules that are not well tolerated by animals, such as toxins, becomes difficult. Furthermore antibodies against molecules that are inherently less immunogenic are also difficult to rise.

The identification and production of monoclonal antibodies is laborious and can become very expensive (Berkower, 1996). Moreover, the production of antibodies has challenges of its own. Frozen stocks of antibody-producing cells should be stored at multiple sites to overcome accidental losses or death of cell lines (Berkower, 1996). Typically, growing the hybridomas in the peritoneal cavities of animals and purifying the antibody from ascitic fluid results high yields of monoclonal antibodies. However, hybridomas are difficult to grow in vivo, thus restricting this route of antibody production (Berkower, 1996). By and large, the generation of hybridomas are restricted to rat and mouse, limiting the use of antibodies in therapeutic applications. Some advances have been achived in this area with the emergence of combinatorial library technology, where antibodies are selected from a library expressed on the surface of M13 filamentous phage and then panned in an antigen dependent manner (Clackson et al., 1991; Huse et al., 1999). Antibodies of nonhuman origin have implications in diagnostic applications as well. Heterophilic antibodies (human antibodies that recognize antibodies of non-human origin) that exist in humans could potentially link a capture antibody with a detector antibody of non-human origin in the absence of the specific analyte, leading to false-positive results. Rheumatoid factors and auto-antibodies have been shown to interfere with immunoassays (Kosmas et al., 1993).

The performance of the same antibody tends to vary from batch to batch, requiring immunoassays to be re-optimised with each new batch of antibodies. As the production of antibodies is subject to in vivo variations, the identification of antibodies is also restricted by in vivo parameters. In other words, identification of antibodies that could recognize targets under conditions other than physiological is not feasible. The kinetic parameters of antibody-target interactions cannot be changed on demand. Antibodies are sensitive to temperature and undergo irreversible denaturation. They also have a limited shelf life (Berkower, 1996).
It is however important to outline that various approaches are being developed to circumvent limitations associated with the current hybridomabased antibody technology. These approaches include the well-established humanization of antibodies (Hwang and Foote, 2005), displaying peptide libraries on phage display technology (Fitzgerald, 2000), ribosomes (Glickman and Raveh, 2005), yeast two-hybrid system for selecting functional intrabodies (Hyland et al., 2003), single chain antibodies (Tungpradabkul et al., 2005), and they are all at various stages of development.

Alternatively, aptamers have been developed in the last decade alongside antibodies with the promise of being equal or superior molecules that can overcome certain disadvantages of the antibody technology (Jayasena, 1999), as outlined in the previous sections. Aptamers chief advantage lies on their technical versatility and applicability to a wide array of target molecules. It is expected that certain applications that use antibodies will gradually be used in conjunction or replaced by aptamers because of their inherent characteristics (Nimjee, 2005). The question now remains whether these advantages are unique enough to prompt researchers to overcome some of the daunting disadvantages and establish aptamers as diagnostic and therapeutic agents in the clinic.

\section{RESUMO}

Aptâmeros são pequenos oligonucleotídeos de cadeia simples, que têm sido desenvolvidos nos últimos 15 anos para diversos alvos e com várias aplicações. Essas incluem a inibição de receptores e enzimas, para a identificação de pequenas moléculas "sensoras" e o desenvolvimento de alvos terapêuticos para diagnóstico e imagem. Além disso, aptâmeros também foram desenvolvidos para alvos que incluem diferentes doenças, tais como HIV, doenças tropicais, câncer e inflamação. $O$ fácil desenvolvimento, flexibilidade de uso e manipulação sugere outras aplicações potenciais. Esta revisão apresenta uma seleção de trabalhos e considera alguns dos mais recentes usos dos aptâmeros para o desenvolvimento de radiofármacos para radioterapia e diagnóstico por imagens. 


\section{REFERENCES}

Andreola, M. L., Pileur, F., Calmels, C., Ventura, M., Tarrago-Litvak L., Toulme, J. J., Litvak, S. (2001), DNA aptamers selected against the HIV-1 RNase H display in vitro antiviral activity. Biochemistry, 40, 10087-10094.

Berens, C., Thain, A., Schroeder, R. (2001), A tetracycline-binding RNA aptamer. Bioorg. Med. Chem., 9, 2549-2556.

Berkower, I. (1996), The promisse and pitfalls of monoclonal antibody therapeutics. Current Opin. Biotechnol., 7, 622-628.

Bernardo-Filho, M., Santos-Filho, S., Moura, E., Maiworm, A., Orlando, M., Penas, M., Cardoso, V., Bernardo, L., Brito, L. (2005), Drug interaction with radiopharmaceutical: a review. Braz. Arch. Biol. Technol., 48, 13-27.

Biroccio, A., Hamm, J., Incitti, I., De Francesco, R., Tomei, L. (2002), Selection of RNA aptamers that are specific and high-affinity ligands of the hepatitis $\mathrm{C}$ virus RNA-dependent RNA polymerase. J. Virol., 76, 3688-3696.

Blank, M., Weinschenk, T., Priemer, M., Schluesener, H. (2001), Systematic evolution of a DNA aptamer binding to rat brain tumor microvessels. Selective targeting of endothelial regulatory protein pigpen. $J$. Biol. Chem., 276, 16464-16468.

Bock, L. C., Griffin, L. C., Latham, J. A., Vermaas, E. H., Toole, J. J. (1992), Selection of single-stranded DNA molecules that bind and inhibit human thrombin. Nature, 355, 564-566.

Borbas, K. E., Ferreira, C. S. M., Perkins, A., Bruce, J. I., Missailidis, S. (2007), Design and synthesis of mono- and multimeric targeted radiopharmaceuticals based on novel cyclen ligands coupled to anti-MUC1 aptamers for the diagnostic imaging and targeted radiotherapy of cancer. Bioconjugate Chem. (in press).

Breaker, R. R. (1997), DNA aptamers and DNA enzymes. Current Opin. Chem. Biol., 1, 26-31.

Britz-Cunningham, S. H., Adelstein, S. J. (2003), Molecular targeting with radionuclides: state of the science. J. Nucl. Med., 44, 1945-1961.

Brody, E. N., Gold, L. (2000), Aptamers as therapeutic and diagnostic agents. Rev. Mol. Biotech., 74, 5-13.

Burgstaller, P., Famulok, M. (1996), Structural characterization of a flavin-specific RNA aptamer by chemical probing. Bioorg. Med. Chem. Letters, 6, 1157-1162.

Carrasquillo, K. G., Ricker, J. A., Rigas, I. K., Miller, J. W., Gragoudas, E. S., Adamis, A. P. (2003), Controlled delivery of the anti-VEGF aptamer EYE001 with poly(lactic-co-glycolic)acid microspheres. Investigative Ophthalmology and Visual Science, 44, 290-299.
Cerchia, L., Hamm, J., Libri, D., Tavitian, B., de Franciscis, V. (2002), Nucleic acid aptamers in cancer medicine. FEBS Lett, 528, 12-16.

Charlton, J., Sennello, J., Smith, D. (1997), In vivo imaging of inflammation using an aptamer inhibitor of human neutrophil elastase. Chem. Biol., 11, 809816.

Clackson, T., Hoogenboom, H. R., Griffiths, A. D., Winter, G. (1991), Making antibody fragments using phage display libraries. Nature, 352, 624-628.

Daniels, D. A., Chen, H., Hicke, B. J., Swiderek, K.M., Gold, L. (2003), A tenascin-C aptamer identified by tumor cell SELEX: Systematic evolution of ligands by exponential enrichment. Proc. Natl. Acad. Sci., USA, 100, 15416-15421.

de Soultrait, V. R., Lozach, P. Y., Altmeyer, R., Tarrago-Litvak, L., Litvak, S., Andreola, M. L. (2002), DNA Aptamers Derived from HIV-1 RNase $\mathrm{H}$ Inhibitors are Strong Anti-integrase Agents. J. Mol. Biol., 324, 195-203.

Deng, Q., German, I., Buchanan, D., Kennedy, R. T. (2001), Retention and separation of adenosine and analogues by affinity chromatography with an aptamer stationary phase. Anal. Chem., 73, 54155421.

Dey, A. K., Khati, M., Tang, M., Wyatt, R., Lea, S. M, James, W. (2005), An aptamer that neutralizes R5 strains of human immunodeficiency virus type 1 blocks gp120-CCR5 interaction. J. Virol., 79, 1380613810.

Dieckmann, T., Butcher, S. E., Sassanfar, M., Szostak, J. W., Feigon, J. (1997), Mutant ATP-binding RNA aptamers reveal the structural basis for ligand binding1. J. Mol. Biol., 273, 467-478.

Dieckmann, T., Suzuki, E., Nakamura, G. K., Feigon, J. (1996), Solution structure of an ATP-binding RNA aptamer reveals a novel fold. $R N A, 2,628-640$.

Dougan, H. W. J., Stafford, A. R., Gillespie, K. D., Klement, P., Hobbs, J. B.; Lyster, D. M. (2003), Evaluation of DNA aptamers directed to thrombin as potential thrombus imaging agents. Nucl. Med. Biol., 30, 61-72.

Duzgunes, N., Simoes, S., Konopka, K., Rossi, J. J., Pedroso de Lima, M. C. (2001), Delivery of novel macromolecular drugs against HIV-1. Expert Opinion On Biological Therapy, 1, 949-970.

Eaton, B.E., Gold, L., Hicke, B.J., Janjie, N., Jucker, F. M., Sebesta, D. P., Tarasow, T. M., Willis, M. C., Zichi, D. A. (1997), Post-SELEX combinatorial optimization of aptamers. Bioorg. Med. Chem., 5, 1087-1096.

Fabbrizio, E., Le Cam, L., Polanowska, J., Kaczorek, M., Brent, R., Sardet, C. (1999), Inhibition of mammalian cell proliferation by genetically selected peptide aptamers that functionally antagonize E2F activity. Oncogene, 18, 4357-4363. 
Famulok, M., Blind, M., Mayer, G. (2001), Intramers as promising new tools in functional proteomics. Chemistry and Biology, 8, 931-939.

Fan, P., Suri,A. K., Fiala, R., Live, D., Patel, D. J. (1996), Molecular Recognition in the FMN - RNA Aptamer Complex. J. Mol. Biol., 258, 480-500.

Feigon, J., Dieckmann, T., Smith, F. W. (1996), Aptamer structures from A to [zeta]. Chem. Biol., 3, 611-617.

Fitzgerald, K. (2000), In vitro display technologies-new tools for drug discovery. Drug Disc. Today, 5, 253-8.

Gewirtz, A. M. (1999), Oligonucleotide therapeutics: clothing the emperor. Current Opin. Mo.l Therapeutics, 1, 297-306.

Glickman, M., Raveh, D. (2005), Proteosome plasticity. FEBBS Lett., 579, 3214-3223.

Griffin, L. C., Toole, J. J., Leung, L. L. K. (1993), The discovery and characterization of a novel nucleotidebased thrombin inhibitor. Gene, 137, 25-31.

Guckian, K. M. Krugh, K. T., Kool, E. T. (1998), Solution structure of a DNA duplex containing a replicable difluorotoluene-adenine pair. Nat. Struc. Biol., 5, 954-959.

Hale, S. P., Schimmel, P. (1996), Protein synthesis editing by a DNA aptamer. Proc. Natl. Acad. Sci. USA, 93, 2755-2758.

Hermann, T. P. D. (2000), Adaptative recognition by nucleic acid aptamers. Science, 287, 820-825.

Hicke, B. J., Stephens, A. W., Gould, T., Chang, Y.F., Lynott, C.K., Heil, J., Borkowski, S., Hilger, C. S., Cook, G., Warren, S., Schmidt, P. G. (2006), Tumor targeting by an aptamer. J. Nucl. Med., 47, 668-678.

Hilger, C. S., Willis, M. C., Wolters, M., Pieken, W. A. (1998), Synthesis of Tc-99m-labeled, modified RNA. Tetrahedron Lett., 39, 9403-9406.

Holland, C. A., Henry, A.T., Whinna, H. C., Church ,F. C. (2000), Effect of oligodeoxynucleotide thrombin aptamer on thrombin inhibition by heparin cofactor II and antithrombin. FEBS Lett., 484, 87-91.

Homann, M., Goringer, H. U. (1999), Combinatorial selection of high affinity RNA ligands to live African trypanosomes. Nucleic. Acids. Res., 27, 2006-2014.

Homann, M., Goringer, H. U. (2001), Uptake and intracellular transport of RNA Aptamers in African trypanosomes suggest therapeutic "Piggy-Back" approach. Bioorg. Med. Chem., 9, 2571-2580.

Huse, W. D., Sastry, L., Iverson, S. A., Kang, A. S., Alting-Mees, M., Burton, D. R., Benkovic, S. J., Lemer, R. A. (1989), Generation of a large combinatorial library of the immunoglobulin repertoire in phage lambda. Science, 246, 1275-1281.

Hwang, J., Fauzi, H., Fukuda, K., Sekiya, S., Kakiuchi, N., Shimotohno, K., Taira, K., Kusakabe, I., Nishikawa, S. (2000), The RNA Aptamer-Binding Site of Hepatitis C Virus NS3 Protease. Biochem. Biophys. Res. Comm., 279, 557-562.
Hwang, W., Foote, J. (2005), Immunogenicity of engineered antibodies. Methods, 36, 3-10.

Hyland, S., Beerli, R. R., Barbas, C. F., Hynes, N. E., Wels, W. (2003), Generation and functional characterization of intracellular antibodies interacting with the kinase domain of human EGF receptor. Oncogene, 22, 1557-1567.

Jayasena, S.D. (1999), Aptamers: an emerging class of molecules that rival antibodies in diagnostics. Clin. Chem., 45, 1628-1650

Kankia, B. I., Marky, L. A. (2001), Folding of the thrombin aptamer into a G-quadruplex with $\operatorname{Sr}(2+)$ : stability, heat, and hydration. J. Am. Chem. Soc., 123, 10799-10804.

Khati, M., Schuman, M., Ibrahim, J., Sattentau, Q., Gordon, S., James, W. (2003), Neutralization of infectivity of diverse R5 clinical isolates of human immunodeficiency virus type 1 by gp120-binding 2 'FRNA aptamers. J. Virol., 77, 12692-12698.

Knight, R., Yarus M. (2003), Analyzing partially randomized nucleic acid pools: straight dope on doping. Nucleic. Acids. Res., 31, 30.

Kosmas, C., Linardou, H., Epenetos, A. A. (1993), Review: advances in monoclonal antibody tumour targeting. J. Drug Target., 1, 81-91.

Kourlas, H., Schiller, D. S. (2006), Pegaptanib Sodium for the Treatment of Neovascular Age-Related Macular Degeneration: A Review Clinical Ther., 28, 36-44.

Lathan, J. A. J. R., Toole, J. J. (1994), The application of a modified nucleotide in aptamer selection: novel trombin aptamers containing 5-(-1pentynyl)-2'deoxyuridine. Nucleic. Acids. Res., 22, 2817-2822.

Le Tinevez, R., Mishra, R. K., Toulme, J. J. (1998), Selective inhibition of cell-free translation by oligonucleotides targeted to a mRNA hairpin structure. Nucleic. Acids. Res., 26, 2273-2278.

Lin, C. H., Patel, D.J. (1996), Encapsulating an amino acid in a DNA fold. Nature Structural Biology, 3, 1046-1050.

Lupold, S. E., Hicke, B., Lin, Y., Coffey, D. S. (2002), Identification and characterization of nucleasestabilized RNA molecules that bind human prostate cancer cells via the prostate-specific membrane antigen. Cancer Res., 62, 4029-4033.

Macaya, R. F. W. J., Beutel, B. A., Gao, H., Joesten, M. E., Yang, M., Patel, R., Bertelsen, A. H., Cook, A. F. (1995), Structural and functional characterization of potent antothrombotic oligonucleotides possessing both quadruplex and duplex motifs. Biochemistry, 34, 4478-4492.

Macaya, R. F., Schultze, P., Smith, F. W., Roe, J. A., Feigon, J. (1993), Thrombin-binding DNA aptamer forms a unimolecular quadruplex structure in solution. Proc. Natl. Acad. Sci. USA, 90, 3745-3749. 
Ng, E. W. M., Shima, D. T., Calias, P., Cunningham, E. T. Jr., Guyer, D. R., Adamis, A. P. (2006), Pegaptanib, a targeted anti-VEGF aptamer for ocular vascular disease. Nature Reviews Drug Discovery, 5, 123-132.

Nimjee, S. M., Rusconi, C. P., Sullenger, B. A. (2005), Aptamers: an emerging class of therapeutics. Annu. Rev. Med., 56, 555-583.

Patel, D. J., Suri, A. K., Jiang, F., Jiang, L., Fan, P., Kumar, R. A., Nonin, S. (1997), Structure, recognition and adaptive binding in RNA aptamer complexes. J. Mol. Biol., 272, 645-664.

Patel, D. J., Suri, A. K. (2000), Structure, recognition and discrimination in RNA aptamer complexes with cofactors, amino acids, drugs and aminoglycoside antibiotics. Rev. Mol. Biotechnol., 74, 39-60.

Patel, D. J. (1997), Structural analysis of nucleic acid aptamers. Curren. Opin. Chem. Biol., 1, 32-46.

Pavski, V., Le, X. C. (2001), Detection of human immunodeficiency virus type1 reverse transcriptase using aptamers as probes in affinity capillary electrophoresis. Anal. Chem., 73, 6070-6076.

Pendergrast, P. S., Marsh, H. N., Grate, D., Healy, J. M., Stanton, M. (2005), Nucleic Acid aptamers for target validation and therapeutic applications. $J$ .Biomol. Tech., 16, 224-234.

Picirilli, J. A. K. T., Moroney, S. E., Benner, S. A. (1990), Enzymatic incorporation of a new base pair into DNA and RNA extends the genetic alphabet. Nature, 343, 33-37.

Pileur, F., Andreola, M. L., Dausse, E., Michel, J., Moreau, S., Yamada, H., Gaidamakov, S. A., Crouch, R. J., Toulme, J. J., Cazenave, C. (2003), Selective inhibitory DNA aptamers of the human RNase H1. Nucleic. Acids. Res., 31, 5776-5788.

Potyrailo, R. A., Conrad, R. C., Ellington, A. D., Hieftje, G. M. (1998), Adapting selected nucleic acid ligands (aptamers) to biosensors. Anal. Chem., 70, 3419-3425.

Rhie, A., Kirby, L., Sayer, N., Wellesley, R., Disterer, P., Sylvester, I., Gill, A., Hope, J., James, W., TahiriAlaouri, A. (2003), Characterization of 2'-fluoroRNA aptamers that bind preferentially to diseaseassociated conformations of prion protein and inhibit conversion. J. Biol. Chem., 278, 39697-39705.

Robertson, S. A. H. K., Frankel, A.D., Wemmer, D.E. (2000), Structure determination and binding kinetics of a DNA aptamer-arginimide complex. Biochemistry, 39, 946-954.

Santulli-Marotto, S., Nair, S. K., Rusconi, C., Sullenger, B., Gilboa, E. (2003), Multivalent RNA aptamers that inhibit CTLA-4 and enhance tumor immunity. Cancer Res., 63, 7483-7489.
Sayer, N. M., Cubin, M., Rhie, A., Bullock, M., TahiriAlaoui, A., James, W. (2004), Structural determinants of conformationally selective, prion-binding aptamers. J. Biol. Chem., 279, 13102-13109.

Schlosser, K., Lam, J.C., Li, Y. (2006), Characterization of long RNA-cleaving deoxyribozymes with short catalytic cores: the effect of excess sequence elements on the outcome of in vitro selection. Nucleic. Acids. Res., 34, 2445-2454.

Schmidt, K. S., Borkowski, S., Kurreck, J., Stephens, A. W., Bald, R., Hecht, M., Friebe, M., Dinkelborg, L., Erdmann, V. A. (2004), Application of locked nucleic acids to improve aptamer in vivo stability and targeting function. Nucleic. Acids. Res., 32, 57555765.

Schneider, D. J. F. J., Hostomosky, Z., Gold, L. (1995), High-affinity ssDNA inhibitors of the reverse transcriptase of type 1human immunodeficiency virus. Biochemistry, 34, 9599-9610.

Sooter, L. J., Ellington, A. D. (2002), Reflections on a Novel Therapeutic Candidate. Chemistry and Biology, 9, 857-858.

Tor, Y. D. P. (1993), Site-specific enzymatic incorporation of an unnatural base N6-(6aminohexyl)isoguanine, into RNA. J. Am. Chem. Soc., 115, 4461-4467.

Tsiang, M. G. C., Griffin, L. C., Dunn, K. E., Leung, L. K. (1995), Selection of a suppressor mutation that restores affinity of an oligonucleotide inhibitor for thrombin using in vivo genetics. J. Biol. Chem., 270, 19370-19376.

Tuerk, C.; Gold, L. (1990), Systematic evolution of ligands by exponential enrichment: RNA ligands to bacteriophage T4 DNA polymerase. Science, 3, 505510.

Tungpradabkul, S., Sandee, D., Puthong, S., Laohathai, K. (2005), Construction of $\mathrm{scFv}$ derived from a tumor-associated monoclonal antibody having tumoricidal activity on human hepatocellular carcinoma. Mol. Immunol., 42, 713-719.

Ulrich, H., Magdesian, M. H., Alves, M. J. M., Colli, W. (2002), In vitro selection of RNA aptamers that bind to cell adhesion receptors of Trypanosoma cruzi and inhibit cell invasion. J. Biol. Chem., 277, 2075620762.

Urbain, J. L. (1999), Oncogenes, cancer and imaging. $J$. Nucl. Med., 40, 498-504.

Vo, N. V., Oh, J-W., Lai, M. M. C. (2003), Identification of RNA ligands that bind hepatitis C virus polymerase selectively and inhibit its RNA synthesis from the natural viral RNA templates. Virology, 307, 301-316.

Weiss, S. P. D., Neumann, M., Groschup, M. H., Kretzschar, H. A., Famulok, M., Winnacker, E. L. (1997), RNA aptamers specifically interact with the prion protein PrP. J. Virol., 71, 8790-8797. 
White, R. R., Shan, S., Rusconi, C. P., Shetty, G., Dewhirst, M. W., Kontos, C. D., Sullenger, B. A. (2003), Inhibition of rat corneal angiogenesis by a nuclease-resistant RNA aptamer specific for angiopoietin-2. Proc. Natl. Acad. Sci. USA, 100, 5028-5033.

Williamson, J. (1994), G-quartet strcutures in telomeric DNA. Annu. Rev. Biophysics Biomol. Struct., 23, 703-730.

Ye, X., Gorin, A., Frederick, R., Hu, W., Majumdar, A., $\mathrm{Xu}, \mathrm{W}$., McLendon, G., Ellington, A., Patel, D. J. (1999), RNA architecture dictates the conformations of a bound peptide. Chem. Biol., 6, 657-669.

Received: July 31, 2007; Revised: August 08, 2007; Accepted: August 10, 2007. 